\title{
Head-space gas liquid chromatography for rapid detection of Escherichia coli and Proteus mirabilis in urine
}

\author{
P. J. COLOE
}

From the Department of Microbiology, Monash University Medical School, Prahran, Victoria, Australia 3181

SUMMARY Measuring ethanol formed from arabinose by Escherichia coli and dimethyl disulphide formed from methionine by Proteus mirabilis is a rapid way of detecting these organisms in the urine. Ethanol and dimethyl disulphide are detected by head-space gas-liquid chromatography. Since sedimented organisms and not whole urine are used the method is not subject to interference from compounds within the urine. When it was tested on 122 samples of urine, 94 from patients with suspected urinary infection and 28 supposedly uninfected control specimens, the results correlated well with viable counts by a conventional bacteriological method. As well as being rapid (results available in four hours) the method is reliable, easy to use, and could be automated. It now requires extensive testing in a hospital laboratory.

Rapid screening methods for detecting urinary infections have been sought for years. Accuracy is necessary because urinary tract infection (UTI) may be asymptomatic (Constable, 1975) and persist undiagnosed for a long period (Freeman and Sindu, 1974). Laboratory methods for detecting bacteriuria are hampered by the contamination of urine that invariably happens during voiding. To overcome this Kass (1956) described a criterion for UTI based on the quantitative estimation of bacteria in midstream specimens of urine. Nevertheless, most screening methods indicate only the presence of organisms and not their number. More recent culture methods such as the use of dip-slides (Craig and Kunin, 1972) do show the number of organisms present, but they are only marginally faster than routine culture methods and cannot be called rapid.

This paper describes a rapid way of quantifying Escherichia coli and Proteus mirabilis in urine by a method based on those of Coloe (1978) and Hayward et al. (1977).

\section{Material and methods}

The method was tested on 122 urine samples, of which 94 were from patients with suspected UTI and 28 were control samples from healthy persons with no recent history of UTI. Care was taken to ensure

Received for publication 12 October 1977 that all were midstream specimens. Only the predominant organism was studied in detail provided it was well in excess of the contaminants that were often present.

To sediment all the organisms $60 \mathrm{ml}$ urine was centrifuged at $1000 \mathrm{~g}$ in a swing-out-bucket rotor of a Mistral $4 \mathrm{~L}$ centrifuge for 10 minutes at $4^{\circ} \mathrm{C}$. The supernatant was discarded and the sediment resuspended in $6 \mathrm{ml}$ yeast-extract peptone water enriched with arabinose and methionine. The suspension was transferred to a 28-ml screw-capped bottle and incubated with shaking at $37^{\circ} \mathrm{C}$ for four hours. The resulting culture was examined for ethanol and dimethyl disulphide by means of head-space gasliquid chromatography as described by Coloe (1978).

Ethanol and dimethyl disulphide produced from bacterial cultures were measured by comparing the retention times of peaks with peaks from standard aqueous solutions of ethanol and dimethyl disulphide. They were confirmed as ethanol and dimethyl disulphide by mass spectrometery. Yields of ethanol and dimethyl disulphide were expressed as peak area in $\mathrm{cm}^{2}$, the area under the peak on the gas-liquid chromatograph chart.

Peptone water was prepared from Bacteriological Peptone (Oxoid) as described by Cowan and Steel (1965). Peptone water enriched with $0.3 \%$ yeast extract, $0.05 \mathrm{M}$ arabinose (BDH), and $0.1 \mathrm{M}$ methionine $(\mathrm{BDH})$ was prepared in $100 \mathrm{ml}$ lots, adjusted to

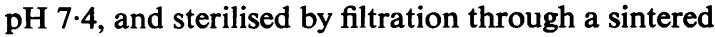


glass filter (Gallenkamp bacteriological filter, porosity 5).

Viable counts were made by the method of Miles et al. (1938). Dilutions were prepared in $1 \%$ peptone water and one drop of each dilution was placed on each of eight MacConkey agar plates and one bloodagar plate. For urine samples from patients with infections other than enterobacteriae viable counts were made on nine blood-agar plates.

\section{Results}

URINE SAMPLES CONTAINING E. COLI

Forty-five samples with counts of $10^{5}$ or more $E$. coli/ $\mathrm{ml}$ were tested. Cultures of all of them yielded ethanol. The average peak area was $440 \mathrm{~cm}^{2}$, the maximum $1200 \mathrm{~cm}^{2}$, and the minimum $95 \mathrm{~cm}^{2}$ (Fig. 1). Forty-two cultures formed a small amount of

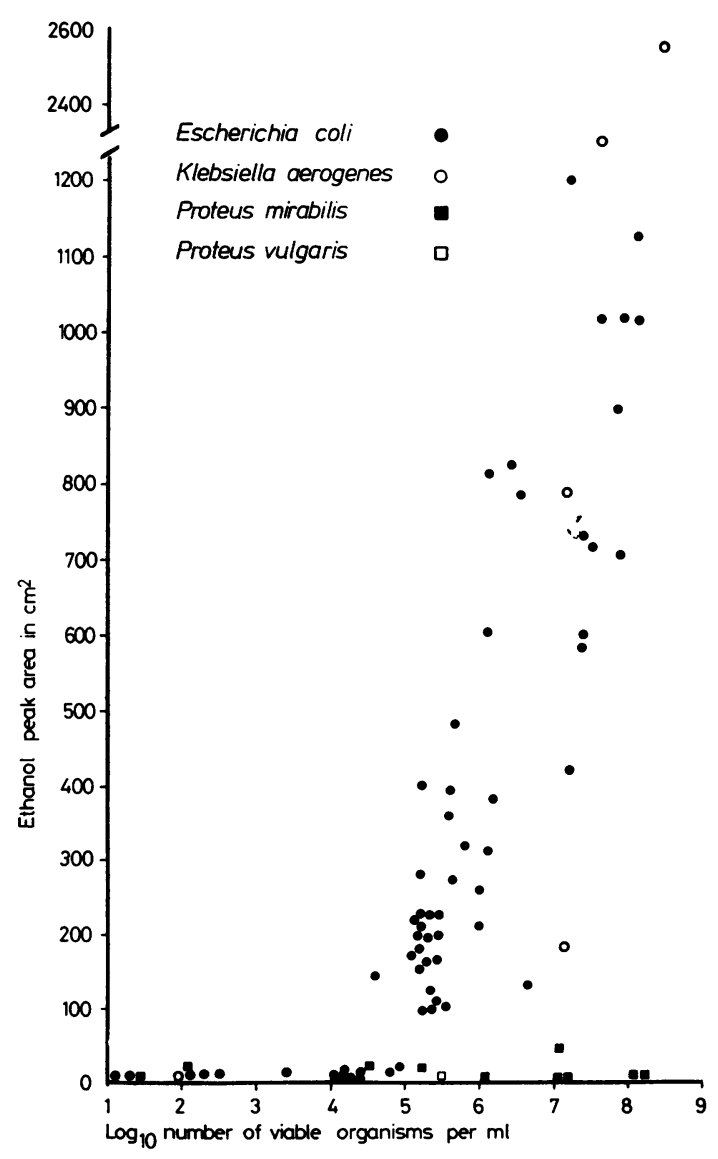

Fig. 1 Scatter plot of ethanol yields detected by headspace gas-liquid chromatography of urine cultures grown in medium enriched with arabinose and methionine. 
$1407 \mathrm{~cm}^{2}$, the maximum $2550 \mathrm{~cm}^{2}$, and the minimum $195 \mathrm{~cm}^{2}$. These yields are as large as those from cultures of urine containing $E$. coli. Three of the four cultures produced dimethyl disulphide. The average yield was $78 \mathrm{~cm}^{2}$ (Fig. 2). Methylmercaptan was not detected in any of the cultures.

Only one urine sample with a count of $10^{4}$ or less was tested. Culture from it yielded a very small amount of ethanol but no dimethyl disulphide (Figs 1, 2).

\section{URINE SAMPLES CONTAINING EITHER}

P. MIRABILIS OR P. VULGARIS

Seven samples containing $10^{5}$ or more $P$. mirabilis $/ \mathrm{ml}$ and one containing $10^{5} P$. vulgaris $/ \mathrm{ml}$ were tested. Ethanol was detected in only two cultures, both from samples containing $\boldsymbol{P}$. mirabilis. The larger amount formed was $45 \mathrm{~cm}^{2}$, less than from any culture of urine with a significant count of $E$. coli (Fig. 1). Large amounts of dimethyl disulphide were formed (Fig. 2). The average peak area was $1563 \mathrm{~cm}^{2}$, the maximum $2200 \mathrm{~cm}^{2}$, and the minimum $570 \mathrm{~cm}^{2}$. This minimum was considerably larger than the yield from any culture of urine containing $E$. coli or $K$. aerogenes. Methylmercaptan was always present but it eluted so quickly that it was impossible to calculate the area of the peak.

Three urine samples that contained $10^{4}$ or fewer $P$. mirabilis/ml were tested. Only two cultures produced any ethanol, the most being $21 \mathrm{~cm}^{2}$ (Fig. 1). All three cultures produced some dimethyl disulphide but the maximum peak area of $355 \mathrm{~cm}^{2}$ was less than from any culture of urine with a significant count of $\boldsymbol{P}$. mirabilis or $\boldsymbol{P}$. vulgaris (Fig. 2). Methylmercaptan was detected in only one of the cultures.

URINE SAMPLES CONTAINING OTHER

BACTERIAL SPECIES

Five urine samples with $10^{5}$ or more Streptococcus faecalis per $\mathrm{ml}$, two with $10^{5}$ or more Staphylococcus epidermidis per $\mathrm{ml}$ and two with less than $10^{5}$ Staphylococcus epidermidis per $\mathrm{ml}$ were tested. None of the cultures formed any ethanol, dimethyl disulphide, or methylmercaptan.

URINE SAMPLES CONTAINING BOTH E. COLI AND P. MIRABILIS

Eight urine samples that contained $10^{5}$ or more per $\mathrm{ml}$ of both $E$. coli and $P$. mirabilis were tested (Table). All cultures produced some ethanol and some dimethyl disulphide. The amount of ethanol in seven of the cultures was compatible with the count of $E$. coli in the urine. The yield of ethanol from the eighth culture was so small that the count of $E$. coli in the urine would have been mistaken for one that was not significant. The amount of dimethyl disulphide in six of the cultures was compatible with the count of $P$. mirabilis in the urine and methylmercaptan was detected in all of these. However, the yields of dimethyl disulphide from two cultures were less than would have been expected from the counts of $\boldsymbol{P}$. mirabilis. Methylmercaptan was not detected from either of these cultures.

URINE SAMPLES STERILE ON CULTURE

Mid-stream specimens of urine, collected under aseptic conditions from 28 men yielded no organisms on culture. Neither ethanol nor dimethyl disulphide was detected.

\section{Discussion}

The organisms were sedimented and then resuspended in the test medium to ensure that stimulating or inhibitory substances were not carried over into the test medium to influence the result. These substances may be in the urine only temporarily. Consequently they have very little effect on the bacterial count of the

Table Results from urine samples containing $\mathrm{E}$. coli and $\mathrm{P}$. mirabilis

\begin{tabular}{|c|c|c|c|}
\hline $\begin{array}{l}\text { Viable organisms } \\
(\text { No. } / \mathrm{ml})\end{array}$ & $\begin{array}{l}\text { Ethanol produced } \\
\left.\text { (peak area in } \mathrm{cm}^{2}\right)\end{array}$ & $\begin{array}{l}\text { Dimethyl disulphide produced } \\
\left.\text { (peak area in } \mathrm{cm}^{2}\right)\end{array}$ & Methyl-mercaptan present \\
\hline 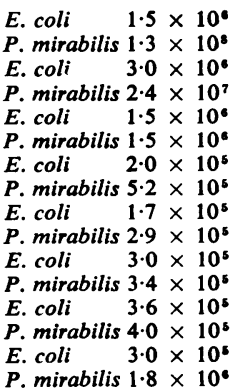 & $\begin{array}{r}600 \\
460 \\
825 \\
330 \\
300 \\
554 \\
360 \\
30\end{array}$ & $\begin{array}{r}1215 \\
460 \\
1490 \\
1430 \\
2110 \\
1950 \\
910 \\
135\end{array}$ & $\begin{array}{l}+ \\
- \\
+ \\
+ \\
+ \\
+ \\
+ \\
-\end{array}$ \\
\hline
\end{tabular}


urine but possibly considerable effect on the result of any test in which whole urine is used. When antibiotics are present and active in urine the centrifugation and subsequent inoculation into fresh medium may be enough to reduce the concentration of the antibiotic below the minimum inhibitory level. The result would possibly differ from that of routine culture but false-positive results are preferable to false-negatives.

The method seems superior to other screening tests because it is easy to perform, rapid, identifies $E$. coli and $\boldsymbol{P}$. mirabilis, and indicates whether they are present in significant numbers. Everything from collecting the sample to reporting the results can be performed in $4 \frac{1}{2}$ hours. The time may be shortened to $3 \frac{1}{2}$ hours, but then organisms present in smaller numbers might be missed. The time could not be shortened much more because the specific products do not appear until the organisms are in the early logarithmic phase of growth. That is why four hours was selected for the test.

The trial with 122 urine samples showed that the method will determine whether $10^{5}$ or more or less than $10^{5} E$. coli or $P$. mirabilis per $\mathrm{ml}$ of urine are present. If, for the instrument used, a cut-off point of a peak area of $90 \mathrm{~cm}^{2}$ of ethanol is chosen to indicate urine infected with $E$. coli all urine samples with $10^{5}$ or more $E$. coli $/ \mathrm{ml}$ and one with $6.9 \times 10^{4} E$. coli $/ \mathrm{ml}$ would have been diagnosed as infected. The test is consistent with the preference for false positives rather than false negatives. If a cut-off point of a peak area of $500 \mathrm{~cm}^{2}$ of dimethyl disulphide is chosen to indicate $\boldsymbol{P}$. mirabilis infection all urine samples with $10^{5}$ or more $P$. mirabilis $/ \mathrm{ml}$ would have been diagnosed as infected and no urine with less than $10^{5} / \mathrm{ml}$ would have been classed as infected.

Among the 122 urine samples were eight containing significant numbers of $E$. coli and $P$. mirabilis. Only six of the eight would have been identified correctly, one would have been identified as infected only with $E$. coli, and one would have been called uninfected. In the case of the negative result, however, there was evidence that the patient had begun unauthorised antibiotic therapy before the sampling. If the test has any major failings they are likely to be related to cases of mixed infection. The method is well suited for use in a diagnostic laboratory. The medium is simple, its components should be readily available, it is easily prepared, and may be stored for a long period. No special technical expertise is required in preparing, inoculating, or analysing the culture. Ethanol eluted on the gas chromatograph used after 1.5 minutes and dimethyl disulphide after 2.6 minutes. Allowing for a settling down period of about three minutes, samples could be analysed every six minutes.
To reduce the time needed to analyse a large number of samples a dual-column, dual-detector gas chromatograph fitted with two recorders or several gas chromatographs could be used. Alternatively, if only one machine were available the analysis could be performed at a temperature higher than $100^{\circ} \mathrm{C}$, or by using a column with less holding capacity than carbowax. Under these conditions all components would elute more quickly. It would then be helpful to have the recorder directly attached to a computer. The method lends itself to automation, especially with a machine such as the Perkin-Elmer F42 automated head-space gas chromatograph. If such a machine could be attached to a computer the method would be almost completely automated other than the preparation of the culture. Under these conditions it could function 24 hours a day.

Antibiotic sensitivity testing could also be incorporated into the test if a gas chromatograph with a sensitive flame ionisation detector were used. The urine samples, after centrifugation and inoculation into the test medium, could be divided into four before incubation. One of the four would be incubated as the test sample and the other three would each be supplemented with one of the antibiotics used for treating urinary infection and then incubated in the same way as the test sample. If the test sample showed that there were $10^{5}$ or more organisms $/ \mathrm{ml}$ in the urine the antibiotic sensitivities could be determined by analysing the antibiotic-supplemented media. If ethanol or dimethyl disulphide was not detected in an antibiotic-supplemented medium it would indicate that the organism causing the infection was sensitive to that antibiotic.

The method is not perfect as a screening technique but it is better than most. At present it is not envisaged as replacing conventional techniques but rather as detecting infections due to $E$. coli and $P$. mirabilis rapidly. The method would also be useful as a routine screening technique for detecting most asymptomatic urinary infections in pregnant women and in school children since, especially in the latter group, $E$. coli is the organism mainly responsible (Freeman and Sindhu, 1974).

Although the method can distinguish $E$. coli from $P$. mirabilis in urine it does not differentiate $E$. coli and Klebsiella spp. It probably does not differentiate the various Proteus spp, nor does it detect Pseudomonas spp, Strep faecalis, or Staph epidermidis. Tests for these organisms within the confines of the method are desirable.

I thank Dr Nancy Hayward and Professor S. Faine for help and guidance. Also Dr A. J. C. Nicholson, Division of Chemical Physics, Commonwealth Scientific and Industrial Research Organisation, for 
confirming ethanol and dimethyl disulphide by mass spectrometry; and the Department of Microbiology, Alfred Hospital, Melbourne, for help in collecting urine specimens.

\section{References}

Coloe, P. J. (1978). Ethanol formed from arabinose: a rapid method for detecting Escherichia coli. Journal of Clinical Pathology, 31, 361-364.

Constable, P. J. (1975). Urinary infection. In: Screening in General Practice, edited by C. R. Hart, pp. 163-175. Churchill Livingstone, Edinburgh.

Cowan, S. T., and Steel, K. J. (1965). Manual for the Identification of Medical Bacteria. Cambridge University Press, Cambridge.
Craig, W. A., and Kunin, C. M. (1972). Quantitative urine culture method using a plastic 'paddle' containing dual media. Applied Microbiology, 23, 919-922.

Freeman, J. W., and Sindhu, S. S. (1974). A survey for bacteriuria in schoolgirls. Medical Journal of Australia, 1, 135-137.

Hayward, N. J., Jeavons, T. H., Nicholson, A. J. C., and Thornton, A. G. (1977). Development of specific tests for the rapid detection of Escherichia coli and all species of Proteus in urine. Journal of Clinical Microbiology, 6, 195-201.

Kass, E. H. (1956). Asymptomatic infections of the urinary tract. Transactions of the Association of American Physicians, 69, 56-64.

Miles, A. A., Misra, S. S., and Irwin, J. O. (1938). The estimation of the bactericidal power of the blood. Journal of Hygiene, 38, 732-749.

\section{Reports and Bulletins prepared by the Association of Clinical Biochemists}

The following reports and bulletins are published by the Association of Clinical Biochemists. They may be obtained from The Publishing Department, British Medical Journal (ACB Technical Bulletins), B.M.A. House, Tavistock Square, London WC1H 9JR. Overseas readers should remit by British Postal or Money Order.

SCIENTIFIC REVIEWS (price $£ 1 \cdot 00 / \$ 2.00$ each)

1 The assessment of thyroid function March 1971 F. V. FLYNN and J. R. HOBBS

2 Renal function tests suitable for clinical practice January 1972 F. L. MITCHELL, N. VEALL, and R. W. E. WATTS

3 Biochemical tests for the assessment of fetoplacental function May 1975 C. E. WILDE and R. E. OAKEY

4 Test of exocrine pancreatic function March 1977 A. H. GOWENLOCK

TECHNICAL BULLETINS (price $£ 1 \cdot 00 / \$ 2.00$ each)

22 Bilirubin standards and the determination of bilirubin by manual and technicon AutoAnalyzer methods January 1971 BARBARA BILLING, RUTH HASLAM, and N. WALD

23 Interchangeable cells for spectrophotometers and fluorimeters September 1971 S. S. BROWN and A. H. GOWENLOCK

24 Simple tests to detect poisons March 1972 B. w. MEADE et al.

25 Blood gas analysers May 1972 K. DIxoN

26 Kits for enzyme activity determination September 1972 S. B. ROSALKI and D. TARLOW

27 Assessment of pumps suitable for incorporation into existing continuous flow analytical systems November 1972 A. FLECK et al.
28 Routine clinical measurements of transferrin in human serum September 1973 K. DIXON

29 Control materials for clinical biochemistry (5th edition) September 1973 J. F. STEVENS

30 Notes on the quality of performance of serum cholesterol assays September 1973 S. S. BROWN

31 Determination of uric acid in blood and in urine July 1974 R. W. E. WATTS

32 A survey of amino acid analysers readily available in the United Kingdom September 1974 J. E. CARLYLE and P. PURKISS

33 Definitions of some words and terms used in automated analysis November 1974 A. FLECK, R. ROBINSON, S. S. BROWN, and J. R. HOBBS

34 Measurement of albumin in the sera of patients January 1975 LINDA SLATER, P. M. CARTER, and J. R. HOBBS

35 Investigation of the validity of temperature correction factors for serum aspartate and alanine transaminases March 1975 s. B. ROSALKI et al.

36 Factors influencing the assay of creatinine November 1975 J. G. H. COOK

37 A survey of enzyme reaction rate analysers readily available in the United Kingdom July 1977 R. A SAUNDERS and R. F. BURNS

38 Transport of specimens for clinical chemistry analysis November 1977 C. E. WILDE 